\title{
PLATAFORMA SWITCHING: CONSIDERAÇÕES ATUAIS
}

\section{PLATFORM SWITCHING: AN UPDATE}

\author{
Catarine Santos Rocha* \\ Adolfo Saraiva de Miranda Luna* \\ Jéssica Leny Gomes Ferreira* \\ Alessandra Marcondes Aranega* \\ Idelmo Rangel Garcia Júnior ${ }^{* *}$ \\ Júlio Maciel Santos de Araújo***
}

\section{RESUMO}

A utilização de implantes na reabilitação dentária em associação a próteses torna-se um tratamento cada vez mais gradativo e eficiente para aqueles dispostos a recuperar a função mastigatória, fonética e estética de seus elementos dentários, conferindo-lhes naturalidade. O implante consiste num parafuso de titânio instalado através de cirurgia e submetido à osseointegração em maxila ou mandíbula. Sobre a plataforma do implante acopla-se um componente protético de mesmo diâmetro. Todavia, o conceito de Plataforma Switching referese ao uso do componente protético de diâmetro menor quando comparado ao diâmetro da plataforma do implante. Essa técnica faz com que a junção implante-pilar se direcione para a porção mais central distanciandoa da crista óssea alveolar. Esse aspecto tem gerado aceitação por parte dos tecidos duros e moles, evitando a formação de micro-espaços na crista do osso e reduzindo o estresse sobre ele. Estudos comprovam que o uso da plataforma switching em Implantodontia atua na manutenção dos níveis de osso minimizando sua perda e favorecendo a estabilidade primária, embora alguns autores afirmem que essa redução é insignificante. Esperase que esta revisão aflore o interesse de mais pesquisadores, de forma a ampliar o campo de estudo teórico, prático e clínico, a fim de garantir maiores evidências a respeito dos benefícios da plataforma switching e delimitar suas restrições para cada caso.

Descritores: Projeto do implante dentário-pivô • Implantação dentária • Reabsorção óssea.

\section{ABSTRACT}

The use of implants in dental rehabilitation in combination with prosthesis is becoming a more gradual and efficient treatment for those willing to recover the masticatory, phonetic and aesthetic functions of their teeth, providing them with naturalness. The implant consists of a titanium screw installed by means of surgery being submitted to osseointegration in the maxilla or mandible. Above the implant platform a prosthetic component of the same diameter is coupled. However, the concept of platform switching refers to the use of the prosthetic component with smaller diameter compared to the diameter of the implant platform. This technique allows the implant-abutment junction to orientate itself towards the more central portion, distancing itself from the bone alveolar crest. This process has generated adaptation by the hard and soft tissues, preventing the formation of micro-spaces in bone crest and reducing the stress on it. Some studies show that the use of platform switching in Implantology actuates in the maintenance of bone levels, minimizing the loss and favoring primary stability, although some authors state that this reduction is insignificant. It is expected that this review flourishes the interest of more researchers in order to increase the theoretical, practical and clinical field of study, to ensure more evidence concerning the benefits of choosing platform switching and define the restrictions for each case.

Descriptors: Dental implant-abutment design • Dental implantation • Bone resorption.

\footnotetext{
* Graduando (a) em Odontologia pelo Centro Universitário de João Pessoa - UNIPÊ.

** Professor (a) Doutor (a) do Departamento de Clínica e Cirurgia Integrada da Faculdade de Odontologia de Araçatuba - Universidade Estadual Paulista Júlio de Mesquita Filho - UNESP. Disciplina de Cirurgia e Traumatologia Bucomaxilofacial.

*** Professor Doutorando pela Faculdade de Odontologia de Araçatuba - Universidade Estadual Paulista Júlio de Mesquita Filho - UNESP. Disciplina de Implantodontia.
} 
ROCHA CS

LUNA ASM

FERREIRA JLM

ARANEGA AM

GARCIA JÚNIOR IR

ARAÚJO JMS

PLATAFORMA

SWITCHING: CON-

SIDERAÇÕES ATUAIS
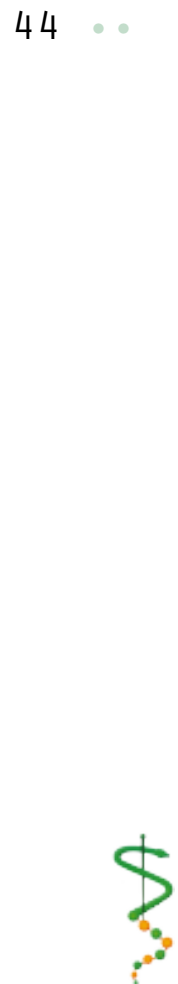

REV, ODONTOL.

UNIV, C I D , SÃO

PAULO

$2015 ; 27(1): 43-$

8, JAN-ABR

\section{N T R O D U ÇÃ O}

A ausência de elementos dentais causa alterações nos processos mastigatórios, fonéticos e digestivos dos pacientes, além de afetar estruturas alveolares, diminuindo o tônus muscular da face. Como consequência, o indivíduo estará susceptível às alterações psicológicas e ao isolamento social ${ }^{1}$. O uso de instrumentos artificiais como motivação para a reabilitação do paciente beneficiará sua vida emocional, devolvendo-Ihe não apenas a função dentária, mas estimulando sua reintegração no convívio em sociedade 2 .

O interesse da população em garantir saúde e beleza abolindo o desconforto e o constrangimento proveniente da perda de dentes é diretamente proporcional aos avanços da Odontologia. Esta, por sua vez, visa à obtenção de tratamentos harmônicos que possam fornecer naturalidade através dos procedimentos reabilitadores em prótese dentária, sejam convencionais ou sobre implantes osseointegrados. Os implantes dentários são parafusos de formas variáveis, confeccionados em titânio, que são cirurgicamente inseridos no osso para que se osseointegrem. Sobre o implante e com o auxílio de cimentos ou parafusos, será acoplada uma coroa protética que se comportará como um elemento dental natural ${ }^{3}$.

Uma crescente incidência pode ser verificada nos tratamentos reabilitadores com implantes osseointegrados utilizando uma espécie de plataforma reduzida, conceituada como Plataforma Switching. Nesse tratamento, o componente protético a ser aplicado apresenta diâmetro menor quando comparado ao diâmetro da plataforma do implante de modo a formar entre eles uma espécie de "degrau". O uso de plataformas switching, segundo a literatura, tem demonstrado uma aceitação por parte dos tecidos moles e duros tanto para os procedimentos de implante realizados em dois estágios quanto para os tratamentos onde se aplica a carga imediata ${ }^{4}$.

Os quadros clínicos em que implantes devem ser colocados em regiões desdentadas estreitas a, no mínimo, $3 \mathrm{~mm}$ de distância um do outro, são indicados para a utilização da plataforma switching, bem como os casos de implantes curtos em áreas atróficas ou quando se deseja obter excelência em estética na região anterior da maxila ${ }^{5}$.

A diminuição do diâmetro do componente protético faz com que a sua junção com a plataforma se direcione para a porção mais central do implante, favorecendo o processo de distribuição de forças. Desse modo, há um deslocamento da interface entre componente e implante no sentido horizontal, direcionado ao centro da plataforma, distanciando-a do osso marginal ${ }^{6}$.

Como consequência do deslocamento da interface ocorre ainda a formação natural dos infiltrados inflamatórios que realizam o selamento da região circundante à plataforma do implante. Assim sendo, o infiltrado bacteriano que migrou para a região mais interior é responsável pela menor reabsorção, ainda que esta também seja influenciada por outros fatores como traumas cirúrgicos e sobrecarga oclusal ${ }^{7}$.

A perda óssea, denominada como saucerização, é um processo que ocorre em implantes osseointegrados de plataforma hexagonal externa e não depende da condição geral do paciente. Para que a reabilitação do paciente através de implantes seja satisfatória a perda óssea alveolar deve ser de aproximadamente 1,5 a 2,0mm. Isso confere o sucesso para a manutenção do implante ${ }^{3,4}$. Estudos através de avaliações radiográficas constatam que o emprego da plataforma switching manteve os níveis da crista óssea, havendo apenas uma perda de osso mínima na porção marginal ${ }^{3}$.

Sendo assim, a concentração do infiltrado inflamatório numa área distante da crista óssea alveolar está diretamente associada à manutenção da altura desses tecidos duros. Esse fator controla o espaço biológico, mantendo a maior altura possível e assegurando resultados estéticos satisfatórios relevantes na reabilitação do paciente ${ }^{8}$.

\section{REVISÃO DE LITERATURA}

Segundo Cumbo et al. ${ }^{9}$ (2013), a estabilidade do osso em torno do implante é fator determinante para o prognóstico favorável de uma reabilitação, principal- 
mente em próteses implantossuportadas. Após a inserção do implante e de seus componentes, a crista óssea sofre processos de reabsorção e remodelação e esse aspecto pode estar relacionado a fatores como sobrecargas oclusais e inflamações nos tecidos moles numa tentativa de restabelecer o espaço biológico. A presença de um microespaço é constatada entre o implante e seu pilar o que possibilita a colonização bacteriana num mecanismo imunológico, resultando assim a perda óssea. Na tentativa de promover a manutenção óssea ao redor dos implantes, foi proposta a Plataforma Switching, uma conexão que move a junção implante-pilar e a ação bacteriana para o centro do implante, afastando-as da crista óssea.

Hürzeler et al..$^{10}$ (2007) afirmam que o uso da plataforma switching é promissor e eficaz para a implantodontia, haja vista que haverá a migração do infiltrado de células inflamatórias para perto da porção central do eixo do implante e distante da crista alveolar de forma a limitar a reabsorção do osso. Esse aspecto beneficiará clinicamente o tratamento reabilitador em estética, o contato do implante e a estabilidade primária.

Para Abrahamsson e Berglundh ${ }^{11}$ (2009), a ausência de sinais da reabsorção de osso nos exames radiográficos corresponde ao equilíbrio entre implante e os tecidos adjacentes. As alterações encontradas em torno do implante são comuns, porém, ao constatar-se o comprometimento ósseo, este deve ser interpretado e analisado de acordo com o tempo e função do implante. Desse modo, é relevante distinguir a remodelação que ocorre após a instalação do implante da perda óssea marginal ocasionada pelo implante em função.

Fickl et al. ${ }^{12}$ (2010) afirmam que a região peri-implantar de tecido mole é constituída por epitélio e tecido conjuntivo correspondendo a uma área de cobertura biológica de aproximadamente $4 \mathrm{~mm}$. Essa cobertura de tecido mole e a localização da junção implante-pilar têm sido destacadas como fatores principais na remodelação óssea que circunda o implante. $\mathrm{O}$ osso, geralmente, é cercado por $1 \mathrm{~mm}$ de tecido conjuntivo sadio e supõe-se que a remodelação óssea decorrente do implante ocorra para estabelecer a região entre o osso e o infiltrado bacteriano de modo a criar um selamento biológico. Além disso, cerca de $3 \mathrm{~mm}$ de mucosa peri-implantar são necessários para uma vedação eficaz em torno do implante.

Linkevicius et al. ${ }^{13}$ (2010) destacam que o emprego de pilares com o diâmetro reduzido pode restringir a perda da crista óssea em menos de $1,5 \mathrm{~mm}$ sendo este um parâmetro que confere prognóstico favorável aos tratamentos, após um ano da instalação do implante através da plataforma switching, quando comparada às plataformas convencionais que estão relacionadas a níveis de perda óssea de aproximadamente $2 \mathrm{~mm}$.

De acordo com Gurgel-Juarez et al. ${ }^{14}$ (2013), vários fatores complementares ainda estão relacionados com a perda do osso, tais como alterações oclusais, contaminação no microespaço entre pilar e implante, restabelecimento do espaço biológico, modelo do pescoço do implante e traumas cirúrgicos. Todavia, torna-se relevante apontar que a reabsorção deve atingir níveis estáveis, tendo-se em vista que a preservação óssea é fundamental para a estética dos tecidos moles. Por conseguinte, a exigência por parte dos pacientes em busca de tratamentos com estética natural tem sido acobertada por técnicas e procedimentos mais eficazes, tais como o uso da plataforma switching em Implantodontia.

Sammartino et al..$^{15}$ (2014) esclarecem que a utilização da plataforma switching atua através de mecanismos que transferem o infiltrado de células inflamatórias para longe da crista óssea, mantêm a largura biológica e o aumento da distância da junção pilar-implante a partir do nível da crista óssea na forma horizontal, reduzem a possível influência do microespaço na crista óssea, além de diminuírem o stress sobre o osso peri-implante.

Portanto, a instalação do pilar de menor diâmetro no implante, que limita e reduz a reabsorção da crista óssea, conceituada pela plataforma switching, auxilia significativamente na manutenção dos tecidos moles e duros que circundam o implante dentário beneficiando, dessa maneira, a
ROCHA CS

LUNA ASM

FERREIRA JLM

ARANEGA AM

GARCIA JÚNIOR IR

ARAúJO JMS

PLATAFORMA

SWITCHING: CON-

SIDERAÇÕES ATUAIS
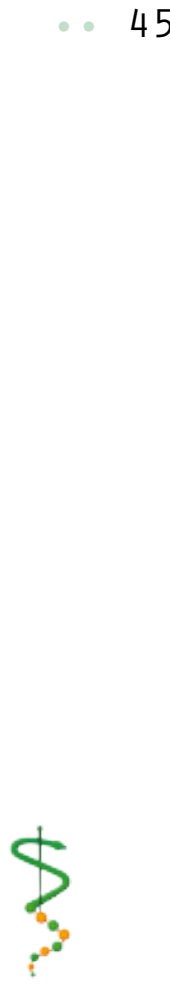

REV. ODONTOL.

UNIV, CID, SÃO

PAULO

$2015 ; 27(1): 43$

8, JAN-ABR 
ROCHA CS

LUNA ASM

FERREIRA JLM

ARANEGA AM : GARCIA JÚNIOR IR

ARAÚJO JMS

PLATAFORMA

SWITCHING: CONSIDERAÇÕES ATUAIS

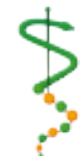

REV, ODONTOL.

UNIV. CID, SÃO

PAULO

$2015 ; 27(1): 43-$

8, JAN-ABR estabilidade primária e estética do caso.

\section{I S CUSSÃO}

No ano de 1991, a 3i Implant Inovations preconizava a fabricação de implantes com o diâmetro mais largo do que as plataformas padrão, no entanto, devido a indisponibilidade de componentes protéticos correspondentes, foi necessária a utilização de pilares protéticos de diâmetro menor $(4,1 \mathrm{~mm})$ em substituição daqueles que possuíam 5 e $6 \mathrm{~mm}$ de diâmetro tal qual o diâmetro do implante. Essa alteração de plataforma de modo não intencional resultou no conceito de Plataforma Switching ${ }^{16}$.

Segundo Schrotenboer et al. ${ }^{17}$ (2008), a mudança da plataforma convencional para a switching refere-se à colocação de um pilar com diâmetro reduzido em relação ao diâmetro da plataforma de fixação, assim, há a mudança de estrutura no sistema de implante que favorece a distribuição do estresse baseado em forças sobre o osso. Ocorre o deslocamento da zona de concentração de tensões dirigindo-as para o longo eixo, ou seja, para a região mais interna do implante. Esse sistema deve suportar a restauração da função, incentivar a fixação óssea, garantir a integridade da prótese e fazer com que as estruturas em torno do implante sejam capazes de se adaptar e suportar forças.

Cappiello et al. ${ }^{18}$ (2008), em estudo clínico e radiográfico realizado para avaliar o efeito biológico da plataforma switching, comprovaram que a reabsorção óssea foi de $0,95 \mathrm{~mm}$ nos implantes com esse tipo de plataforma, enquanto que o grupo-controle apresentou $1,67 \mathrm{~mm}$ de perda óssea. Essa perda corresponde a um aspecto fundamental a ser considerado no sucesso do implante em longo prazo, pois ajudará a descrever o estado peri-implantar servindo-se de instrumento de diagnóstico.

Normalmente, o parâmetro que caracteriza o sucesso e a eficiência do implante é a perda óssea marginal constada pela radiografia no valor de $1,5 \mathrm{~mm}$ no decorrer do primeiro ano de instalação, seguida por uma perda de aproximadamente $0,2 \mathrm{~mm}$ durante cada ano seguinte. Essa condição que avalia o nível do osso ao redor do im- plante é considerada como pré-requisito para preservar a margem gengival e a papila ${ }^{19}$. No entanto, nas pesquisas de Becker et al. ${ }^{20}$ (2009), Canay e Akça ${ }^{21}$ (2009) e Schrotenboer et al..22 (2009), considera-se que a remodelação do osso é mínima e insignificante não havendo importância para a manutenção da crista óssea e redução do estresse sobre a mesma.

No estudo elaborado por Wagenberg e Froum $^{23}$ (2010), avaliou-se por no mínimo onze anos os níveis de crista óssea ao redor de implantes instalados, utilizando-se o conceito de plataforma switching. Nesse estudo, em setenta e um de noventa e quatro implantes $(75,5 \%)$ não havia perda óssea na porção mesial e sessenta e sete deles $(71,3 \%)$ também não apresentaram perda de osso na região distal. Isso indica a relevância da preservação da crista óssea através da plataforma switching.

Em contrapartida, Linkevicius et $a^{13}$ (2010), ao realizarem um estudo piloto, concluíram que implantes com plataforma switching não conservam a crista óssea em maiores proporções quando comparada às plataformas tradicionais. Ressaltaram, ainda, que outros parâmetros, como o tipo de ligação (interno ou externo) e a inclinação do implante, podem ocasionar a perda de osso em região marginal.

Para Salimi et al.5 (2011), os implantes com plataforma switching apresentam uma significativa redução nos processos de reabsorção óssea, quando comparados com a conexão tradicional do implante e seu pilar. Para se obter estética favorável e quantidade de osso suficiente para o suporte do implante, a inibição da reabsorção óssea é um fator essencial. A reabsorção óssea vertical quando presente, por exemplo, se estende de 1 a $2 \mathrm{~mm}$ abaixo da região implante-pilar, podendo desencadear o aumento de tensões no osso. A perda óssea em direção horizontal afeta as regiões interproximais e contribui para a perda de suporte para as papilas. Esses fatores são responsáveis por efeitos biomecânicos que interferem negativamente na reabilitação. Apesar disso, tanto a reabsorção vertical quanto a horizontal são frequentemente observadas em associação a fatores biológicos e mecânicos.

De acordo com González et al.' (2012), 
a perda de osso é atribuída à profundidade de inserção da plataforma e a perda de osso marginal dos implantes com plataforma switching está associada ao seu comprimento, diâmetro, distância interimplante e profundidade. Existem autores que recomendam a instalação da plataforma no nível da crista ou de 1 a $2 \mathrm{~mm}$ abaixo dela, resultando na manutenção óssea marginal de melhor qualidade. Contudo, alguns fatores como a técnica utilizada durante a cirurgia, as técnicas radiográficas de medida e a textura que a plataforma apresenta em sua superfície, podem interferir na relação direta entre a perda de osso e a localização da plataforma switching no mesmo nível, acima ou abaixo da crista óssea. Além disso, os diversos tipos e geometrias de implante influenciam a remodelação do osso após a instalação do implante, independente do nível em que a plataforma foi inserida. Concluiu-se que o uso da plataforma switching e a sua profundidade de inserção são aspectos independentes quando relacionados à reabsorção, ainda que ocorra o aumento na distância horizontal e vertical da área implante-pilar e a crista do osso, e o deslocamento do infiltrado inflamatório com a redução na perda óssea.

Finalmente, Deshpande et al. ${ }^{24}$ (2009) mencionam e defendem diversos benefícios clínicos da plataforma switching, tendo em vista que, com a crista óssea preservada em direção horizontal e vertical, haverá apoio para as papilas interdentais e a conservação da altura óssea ajudará na manutenção dos tecidos gengivais. Assim, a remodelação do osso em menores proporções não potencializará o contato entre osso e implante nos casos de implantes curtos, possibilitando o tratamento de paciente através de terapias menos extensas.

\section{CONCLUSÃO}

A instalação do implante empregando a plataforma switching pode auxiliar na redução da reabsorção de osso, mantendo o nível ósseo circundante ao implante de maneira a preservar os contornos protéticos fisiológicos, munindo-os de uma estética favorável.

\section{REFERÊNCIAS}

ROCHA CS

LUNA ASM

FERREIRA JLM

ARANEGA AM

GARCIA JÚNIOR IR

ARAúJO JMS

PLATAFORMA

SWITCHING: CON-

SIDERAÇÕES ATUAIS
1. Bomfim IPR, Soares DG, Tavares GR, Santos RC, Araujo TP, Padilha WWN. Prevalência de lesões de mucosa bucal em pacientes portadores de prótese dentária. Pesqui bras odontopediatria clín integr 2008 jan-jun;8(1):117-21.

2. Costa APS, Machado FCA, Pereira ALBP, Carreiro AFP, Ferreira MÂF. Qualidade técnica e satisfação relacionadas às próteses totais. Ciênc saúde coletiva 2013 fev;18(2):453-60.

3. Calabrez-Filho S, Cunha N, Calabrez VCN, Calabrez ÂFS. Plataforma reduzida, uma solução estética. Revisão de Literatura. Rev bras odontol 2012 jul-dez;69(2):201-11.

4. Nogueira MCF, Bacchi A, Santos MBF, Mesquita MF, Consani RLX. Efeitos da plataforma switching em reabilitações implantossuportadas: revisão de literatura. RFO, Passo Fundo 2012 jan-abr; 17(1):113-9.
5. Salimi H, Savabi O, Nejatidanesh F. Current results and trends in platform switching. Dent Res J (Isfahan) 2011 Dec;8(Suppl 1):S30-6.

6. Lopez-Mari L, Calvo-Guirado JL, Martin-Castellote B, Gomez-Moreno G, Lopez-Mari M. Implant platform switching concept: an updated review. Med Oral Patol Oral Cir Bucal 2009 Sep;14(9):e450-4.

7. Alonso-González R, Aloy-Prósper A, Peñarrocha-Oltra D, Peñarrocha-Diago MA, Peñarrocha-Diago $M$. Marginal bone loss in relation to platform switching implant insertion depth: An update. J Clin Exp Dent 2012 4(3):e173-e9.

8. Camacho FMT, Sakakura CE, Mera MFM, Esteves JC, Ribeiro FS, Pontes AEF. Avaliação clínica em curto prazo do sistema de Cone Morse e plataforma reduzida em prótese sobre implantes do tipo protocolo: estudo piloto randomizado controlado. Rev odontol UNESP (Online) 2012 jul-ago;41(4): 
ROCHA CS

LUNA ASM :

FERREIRA JLM

ARANEGA AM

GARCIA JÚNIOR IR

ARAÚJO JMS

PLATAFORMA

SWITCHING: CON-

SIDERAÇÕES ATUAIS
9. Cumbo C, Marigo L, Somma F, La Torre G, Minciacchi I, D'Addona A. Implant platform switching concept: a literature review. Eur Rev Med Pharmacol Sci 2013 Feb;17(3):392-7.

10. Hurzeler M, Fickl S, Zuhr O, Wachtel HC. Peri-implant bone level around implants with platform-switched abutments: preliminary data from a prospective study. J Oral Maxillofac Surg 2007 Jul;65(7 Suppl 1):33-9.

11. Abrahamsson I, Berglundh T. Effects of different implant surfaces and designs on marginal bone-level alterations: a review. Clin Oral Implants Res 2009 Sep;20 Suppl 4(207-15.

12. Fickl S, Zuhr O, Stein JM, Hurzeler MB. Peri-implant bone level around implants with platform-switched abutments. Int J Oral Maxillofac Implants 2010 May-Jun;25(3):577-81.

13. Linkevicius T, Apse P, Grybauskas S, Puisys A. Influence of thin mucosal tissues on crestal bone stability around implants with platform switching: a 1-year pilot study. J Oral Maxillofac Surg 2010 Sep;68(9):2272-7.

14. Gurgel-Juarez NC, França FMG, Kina S, Almeida EO, Rocha EP. Bone stress evaluation in implants with regular and Ssitching platforms. RGO - Rev Gaúcha Odontol 2013 out-dez;61(4):573-80.

15. Sammartino G, Cerone V, Gasparro R, Riccitiello F, Trosino O. The platform switching approach to optimize split crest technique. Case Reports Dent 2014 2014(1):1-9.

16. Lazzara RJ, Porter SS. Platform switching: a new concept in implant dentistry for controlling postrestorative crestal bone levels. Int J Periodontics Restorative Dent 2006 Feb;26(1):9-17.
17. Schrotenboer J, Tsao YP, Kinariwala V, Wang HL. Effect of microthreads and platform switching on crestal bone stress levels: a finite element analysis. J Periodontol 2008 Nov;79(11):216672.

18. Cappiello M, Luongo R, Di lorio D, Bugea C, Cocchetto R, Celletti R. Evaluation of peri-implant bone loss around platform-switched implants. Int J Periodontics Restorative Dent 2008 Aug;28(4):347-55.

19. Atieh MA, Ibrahim HM, Atieh AH. Platform switching for marginal bone preservation around dental implants: a systematic review and meta-analysis. J Periodontol 2010 Oct;81(10):135066.

20. Becker J, Ferrari D, Mihatovic I, Sahm N, Schaer A, Schwarz F. Stability of crestal bone level at platform-switched non-submerged titanium implants: a histomorphometrical study in dogs. J Clin Periodontol 2009 Jun;36(6):5329.

21. Canay S, Akca K. Biomechanical aspects of bone-level diameter shifting at implant-abutment interface. Implant Dent 2009 Jun;18(3):239-48.

22. Schrotenboer J, Tsao YP, Kinariwala V, Wang HL. Effect of platform switching on implant crest bone stress: a finite element analysis. Implant Dent 2009 Jun;18(3):260-9.

23. Wagenberg B, Froum SJ. Prospective study of 94 platform-switched implants observed from 1992 to 2006. Int J Periodontics Restorative Dent 2010 Feb;30(1):9-17.

24. Deshpande SS, Sarin SP, Parkhedkar RD. Platform switching of dental implants: panacea for crestal bone loss? . J Clin Diagn Res 2009 3):1348-52.

Recebido em 18/05/2015

Aceito em 22 /05/2015
REV, ODONTOL :

UNIV. CID. SÃO

$2015 ; 27(1): 43-$

8, JAN-ABR 